\title{
Molecular basis of resistance in wheat varieties against spot blotch disease
}

\section{Udai Prakash Singh and Ramji Singh*}

Department of Plant Molecular Biology and Genetic Engineering, N.D. University of Agriculture and Technology Kumarganj, Faizabad (U.P.), INDIA

* Department of Plant Pathology, College of Agriculture, SVP University of Agriculture and Technology, Meerut (U.P.), INDIA

*Corresponding author. E-mail: singh.ramji@gmail.com

\begin{abstract}
During present investigation, among the six wheat genotypes tested against six isolates of Bipolaris sorokiniana, the genotype BOW'S' showed resistance response against three isolates, namely, BS-D-1, BS-DWR$\mathrm{K}-2$ and BS-K-4, whereas moderately resistance response against remaining 3 isolates i.e. BS-F-3, BS-P-5 and BS-V-6. The genotype A-9-30-1 showed almost highly susceptible response against each isolate except BS-D-1 which exhibited susceptible reaction on this genotype. Thus, it is clear that genotype BOW ' $S$ ' has broad genetic base for resistance, whereas genotype A-9-30-1 has no gene for resistance against these six isolates tested. Remaining five genotypes showed varying response, ranging from highly susceptible, susceptible, moderately susceptible, moderately resistant and resistant against various isolates of $B$. sorokiniana tested.
\end{abstract}

Keywords: Resistance, Spot blotch, Primer, Dendrogram, Protein Profiling

\section{INTRODUCTION}

Wheat (Triticum aestivum L. emend. Fiori and Paol.) is the world's most widely cultivated food crop for nearly 38 per cent of the world's population. This crop contributes 33 to $37 \%$ to the national food grain production and will continue to play a crucial role in the food security of the country. The total production of wheat in the world is about 600 million tonnes. The demand for wheat will grow faster than any other major crop as it is estimated that around 1,050 million tonnes of wheat will be required globally for ever growing population by 2020 (Kronstad, 1998), while at the same time Indian demand will be between 105 to 109 million tonnes (Shoran et al., 2005). Among the wheat diseases, wheat rusts, loose smut, karnal bunt and foliar blight/ spot blotch are important one, which cause substantial reduction in yield as well as deterioration in grain quality. Three foliar blights viz., leaf blight, blotches and spots caused by Alternaria spp., Bipolaris spp. and Drechslera spp., respectively, have now become important diseases. Among these spot blotch has now emerged as one of the most serious production constraints in Uttar Pradesh and other northern states causing yield losses of nearly 40.9 per cent and grain weight reduction of 26.1 per cent (Singh et al., 2002). Management of this disease through host resistance has become a prime concern of scientist and farmers as well. Managing any pathogen through host resistance requires a comprehensive knowledge of prevalent races of the target pathogen, which can be achieved by exploring the virulence diversity in pathogen population as well as the genetic diversity of host. Variability in the spot blotch pathogen Bipolaris sorokiniana at pathogenic, morphological and physiological level have been reported (Hetzler et al., 1991, Mariatte et al., 1998 and Chauhan et al., 2007). However, the information so far available on the variability of $B$. sorokiniana isolates seems to be inadequate. The spot blotch resistant gene in wheat are not known to interact in a gene for gene manner, but resistant genotypes are known to show significant reduction in disease development and intensity as compared to the susceptible cultivars (Joshi and Chand, 2002 and Joshi et al., 2002). It is essential to learn as much as possible about the variability in fungi, pathogenic to plants. and also to record the disease reaction of different wheat genotypes to identify sources of resistance against particular disease. Such type of study are not only important for understanding population dynamics of specific pathogen, rather it is equally important for success of any breeding programme for development of disease resistant varieties and to formulate integrated disease management strategy. Such information may also help in marker assisted selection for disease resistance in crops.

\section{MATERIALS AND METHODS}

Collection and maintenance of isolates: The pathogen, Bipolaris sorokiniana was isolated from wheat leaves showing spot blotch symptoms (irregular shape big size brown colour spot). Diseased leaves were collected from different wheat growing areas of north India infected with spot blotch disease on Potato Dextrose Agar (PDA) 
Table 1. Disease severity and reaction of genotypes of wheat inoculated with six isolates of B.sorokiniana.

\begin{tabular}{|c|c|c|c|c|c|c|}
\hline \multirow[t]{2}{*}{ Genotypes } & \multicolumn{6}{|c|}{ Spot blotch severity (\%) exhibited by various isolates } \\
\hline & BS-D-1 & BS-DWR-K-2 & BS-F-3 & BS-K-4 & BS-P-5 & $\overline{B S-V-6}$ \\
\hline \multirow{2}{*}{ BOW 'S' } & 4.99 & 8.87 & 28.45 & 9.51 & 24.89 & 11.57 \\
\hline & $(\mathrm{R})$ & $(\mathrm{R})$ & $(\mathrm{MR})$ & (R) & (MR) & (MR) \\
\hline \multirow{2}{*}{ HUW 234} & 29.58 & 67.10 & 80.79 & 46.85 & 67.98 & 50.95 \\
\hline & $(\mathrm{MR})$ & $(\mathrm{S})$ & (HS) & $(\mathrm{MS})$ & $(\mathrm{S})$ & $(\mathrm{S})$ \\
\hline \multirow{2}{*}{ PBW 343} & 30.45 & 52.92 & 64.39 & 29.64 & 58.88 & 47.60 \\
\hline & $(\mathrm{MS})$ & $(\mathrm{S})$ & $(\mathrm{S})$ & (MR) & $(\mathrm{S})$ & (MS) \\
\hline \multirow{2}{*}{ PBW 443} & 30.40 & 49.28 & 61.85 & 30.74 & 68.25 & 55.91 \\
\hline & (MS) & (MS) & (S) & (MS) & $(\mathrm{S})$ & $(\mathrm{S})$ \\
\hline \multirow{2}{*}{ K 9107} & 25.96 & 25.84 & 70.92 & 70.55 & 68.52 & 48.35 \\
\hline & (MR) & (MR) & (HS) & (HS) & $(\mathrm{S})$ & (MS) \\
\hline \multirow{2}{*}{ A-9-30-1 } & 58.32 & 74.92 & 96.85 & 75.09 & 91.53 & 80.75 \\
\hline & (S) & (HS) & (HS) & (HS) & $(\mathrm{HS})$ & (HS) \\
\hline Mean & 29.95 & 46.48 & 67.20 & 43.73 & 63.34 & 49.18 \\
\hline
\end{tabular}

medium under aseptic condition and Purified through monoconidial isolation (Maraite et al., 1998). Monoconidial isolates maintained from different places were designated accordingly (Table 1) and were used for artificial inoculation.

Inoculation and incubation:Experiment for observing reactions of wheat varieties, (BOW'S', HUW-234, PBW 343, PBW 443, K-9107 and A-9-30-1) weather they are resistant or susceptible, was carried out at 42 to 45 days old plants in glass house. These varieties were selected because they exhibit varying degree of reactions (resistance to highly susceptible) under Kumarganj conditions. Five seedlings of each genotypes were raised in plastic pots. Two hours before inoculation, the plants were kept in humidity chamber, fitted with mistifier to maintain film of water on leaf surface. The plants were inoculated with spore suspension of each test isolate of Bipolaris sorokiniana after pin pricking the leaves. The inoculum was obtained from 20 days old culture of each test isolates, which was grown as mass culture on sterilized sorghum grains. Plants were sprayed with inoculum containing about 70000 to 80000 conidia per milliliter of water and two drops of Tween 20 (polyoxyethelene sorbitan monolaurate) per $100 \mathrm{ml}$ for adherence of spore suspension on plant surface. After inoculation, plants were kept in a moist chamber maintained at 90 to $100 \% \mathrm{RH}$ for about 48 hours. Subsequently, plants were transferred to another chamber of the glass house where temperature may have been between $20-30^{\circ} \mathrm{C}$ (month of February $1^{\text {st }}$ fortnight). Disease rating was done, 21 days after inoculation, when lesions attained its maximum size using the rating scale given by Dubin (1992).

Protein profiling of wheat varieties:Protein profiling from leaves of six different wheat varieties was done by method given by Laemmli (1970). Presence of protein was estimated according to Lowery et al. (1951) method. Appearance of blue color indicated the presence of protein. The concentration of protein was estimated by

optical density at $595 \mathrm{~nm}$ which was measured by a Spectrophotometer (2000 Spectran). The isolated Protein was loaded with loading dye into the wells casted in separating gel (5\%) and run for 8-10 hours with a supply of $25 \mathrm{~mA}$ and 160 Volt Current. In Electrophoresis unit Vertical slab gel type electrophoresis unit (Glass plate 18 x 9 x $0.1 \mathrm{~cm}$.) including Power Pack (ATTO AE 6220, PVT. JAPAN). The Gel was stained by Gel staining solution (coomassie brilliant blue R-250) for 15-20 hr. and then was destained by $10 \%$ menthanol and $5 \%$ acetic acid for final volume of $100 \mathrm{ml}$ to get proper resolution of protein bands.

DNA profiling of wheat varieties and RAPD analysis: Genomic DNA was isolated from young leaves collected and transported in an ice box from the field to the laboratory and subsequently ground in liquid nitrogen using morter and pestle. Total DNA was isolated according to the protocol described by CTAB method Doyle and Doyle (1990) with slight modification. Wheat leaves were homogenized in liquid nitrogen transfer to $50 \mathrm{ml}$ polypropylene centrifuge tube containing $15 \mathrm{ml}$ prewarmed $\left(65^{\circ} \mathrm{C}\right)$ DNA extraction buffer. The suspension was incubated for $1 \mathrm{hr}$ at $65^{\circ} \mathrm{C}$. The mixture was emulsified with an equal volume of chloroform:isoamyl alcohol (24:1) for 5-10 min by inversion followed by centrifugation at $15,000 \mathrm{rpm}$ for $15 \mathrm{~min}$. The aqueous phase was transferred to a fresh centrifuge tube with a wide bore pipette and 0.6 volume of iso-propanol was added to it and mixed by gentle inversion. The precipitated DNA was washed twice by $70 \%$ alcohol. The pellet was dried under vacuum and dissolved in $1 \mathrm{ml}$ of TE buffer. The DNA was purified and its quality and quantity was verified spectrophotometrically.

RAPD analysis was performed following the method given by Kaur et al.(2007). All DNA amplification was carried out in a Thermal cycler (Bio Rad) which was programmed for 1 cycle of $4 \mathrm{~min}$ at $94^{\circ} \mathrm{C}$ followed by 45 cycles of $1 \mathrm{~min} .94^{\circ} \mathrm{C}, 1 \mathrm{~min}$. at $37^{\circ} \mathrm{C}$ and $2 \mathrm{~min}$ at $72^{\circ} \mathrm{C}$. The last extension cycle was programmed at $72^{\circ} \mathrm{C}$ for $7 \mathrm{~min}$. 


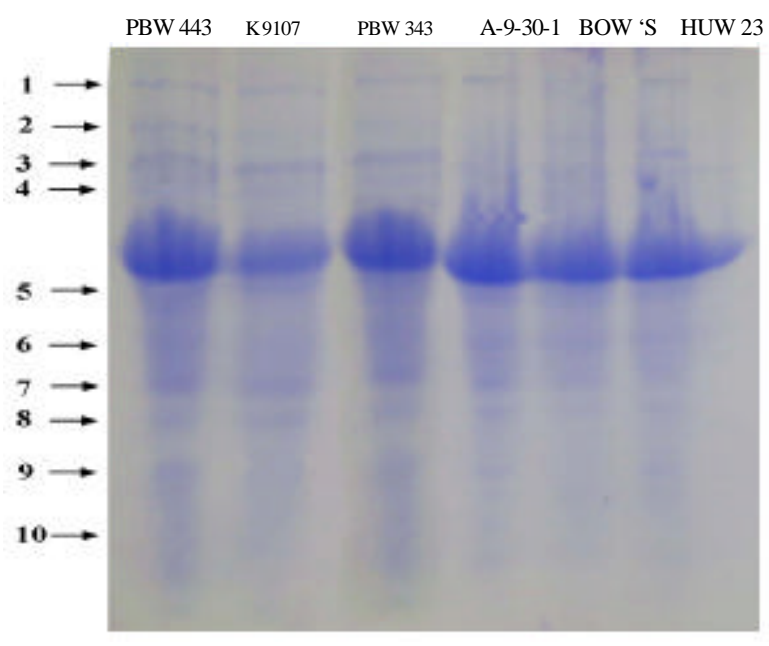

Plate 1. Protein profiling of six wheat genotypes.

The PCR products were resolved in $1.2 \%$ agarose gel after staining in Ethidium Bromide and Photographed using Gel documentation System.

All gels showing DNA bands scored twice independently. Band presence was indicated by 1 and its absence was indicated by 0 . Presence and absence of unique and shared polymorphic as well as monomorphic products were used to generate similarity coefficient. The similarity coefficient were then used to construct a dendrogram UPGMA (Unweighted Pair Group method with arithmetical averages) using a Computer Programme NTSYSPC Version 2.1.

\section{RESULTS AND DISCUSSION}

Disease reactions of wheat varieties: The disease reaction of the six different isolates of $B$. sorokiniana (BS-DWRK-2, BS-D-1, BS-P-5, BS-K-4, BS-F-3 and BS-V-6) on six different host genotypes of wheat have been given in table-1. The genotype PBW 343 was found to be moderately resistant against isolate BS-K-4, moderately susceptible against BS-D-1 and BS-V-6 and susceptible against remaining three isolates i.e. BS-DWR-K-2, BS-F3 and BS-P-5. The genotype PBW 443 was found to be moderately susceptible against BS-D-1, BS-DWR-K-2, and BS-K-4 and susceptible against rest three isolates i.e. BS-P-5, BS-F-3 and BS-V-6. The genotype K 9107 was found to be moderately resistant against BS-DWR-K-2 and BS-D-1 moderately susceptible against BS-V-6, susceptible against BS-P-5 and highly susceptible against BS-K-4 and BS-F-3 isolates. The genotype A-9-30-1 was found to be susceptible to highly susceptible against all the isolates.

Protein profiling of wheat varieties: Protein profiling of six wheat varieties resulted in total 46 protein bands and 10 banding patterns (Plate 1). Among these protein bands, the $1^{\text {st }}$ and $10^{\text {th }}$ protein bands were monomorphic with respect to all the varieties except BOW ' $\mathrm{S}$ ' means, with respect to BOW ' $\mathrm{S}$ ' there was polymorphism in the $1^{\text {st }}$ and

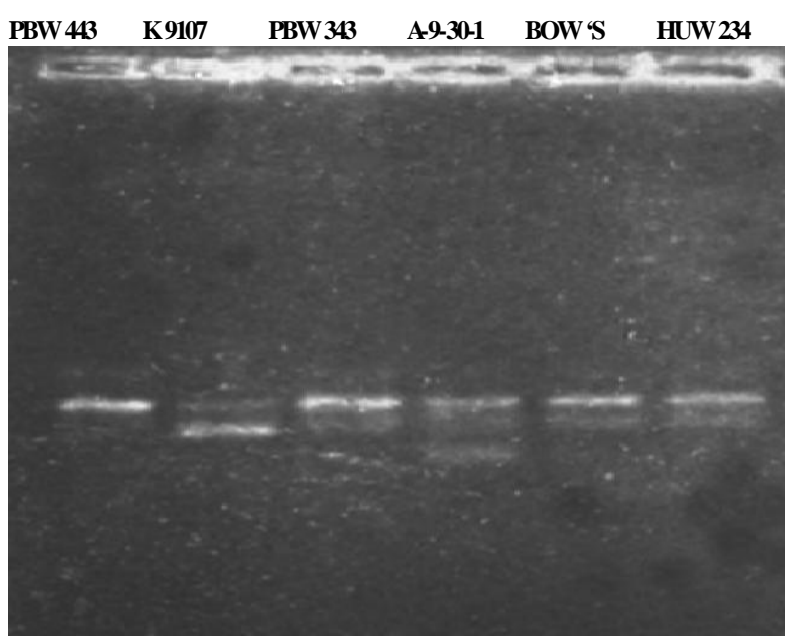

Plate 2. DNA amplification of wheat genotypes by RAPD.

$10^{\text {th }}$ band. In the screening experiment, BOW ' $\mathrm{S}$ ' was the only variety which showed resistant or moderately resistant reaction against all the six isolates of $B$. sorokiniana. Thus the evidence is indicating towards the correlation of $1^{\text {st }}$ and $10^{\text {th }}$ protein bands with susceptibility against spot blotch Similarly the $3^{\text {rd }}$ and $4^{\text {th }}$ protein bands, which were monomorphic in relation to wheat varieties, BOW 'S', HUW-234, PBW-443, PBW-343 and A-9107 but showed polymorphism in relation to he variety A-9-30-1 (susceptible or highly susceptible). Thus the evidential proofs indicate that the $\mathrm{III}^{\mathrm{rd}}$ and $\mathrm{IV}^{\text {th }}$ protein bands may be correlated with resistance against $B$. sorokiniana. It is also clear that wherever the $1^{\text {st }}$ and $10^{\text {th }}$ protein bands are present they are conferring susceptibility and wherever the $\mathrm{III}^{\mathrm{rd}}$ and $\mathrm{IV}^{\text {th }}$ protein bands are present they are conferring resistance. Wherever $1^{\text {st }}$ and $10^{\text {th }}$ bands and $\mathrm{III}^{\text {rd }}$ and $\mathrm{IV}^{\text {th }}$ bands present together, such varieties are either moderately resistant or moderately susceptible, while presence of only $1^{\text {st }}$ and $10^{\text {th }}$ bands confers absolute susceptibility. Similarly presence of $\mathrm{III}^{\mathrm{rd}}$ and $\mathrm{IV}^{\text {th }}$ bands alone provide absolute resistance. There is no earlier report with respect to difference in protein profiles of resistant and susceptible wheat varieties against $B$. sorokiniana causing spot blotch of wheat. However some

Table 2. Showing sequence and no. of bands amplified by primers.

\begin{tabular}{|c|c|c|}
\hline Primer & Sequence & $\begin{array}{l}\text { Total no. of } \\
\text { bands Amplified }\end{array}$ \\
\hline A A-09 & AGATGGGCAG & 21 \\
\hline W - 11 & CTGATGCGTG & 31 \\
\hline W -02 & ACCCCGCCAA & 35 \\
\hline V -07 & GAAGCCAGCC & 12 \\
\hline A H- 18 & GGGCTAGTCA & 29 \\
\hline $\mathrm{W}-01$ & CTCAGTGTCC & 57 \\
\hline $\mathrm{R}-04$ & CCCGTAGCAC & 48 \\
\hline Total & & 233 \\
\hline
\end{tabular}


Table 3. Similarity coefficient matrix of six wheat varieties.

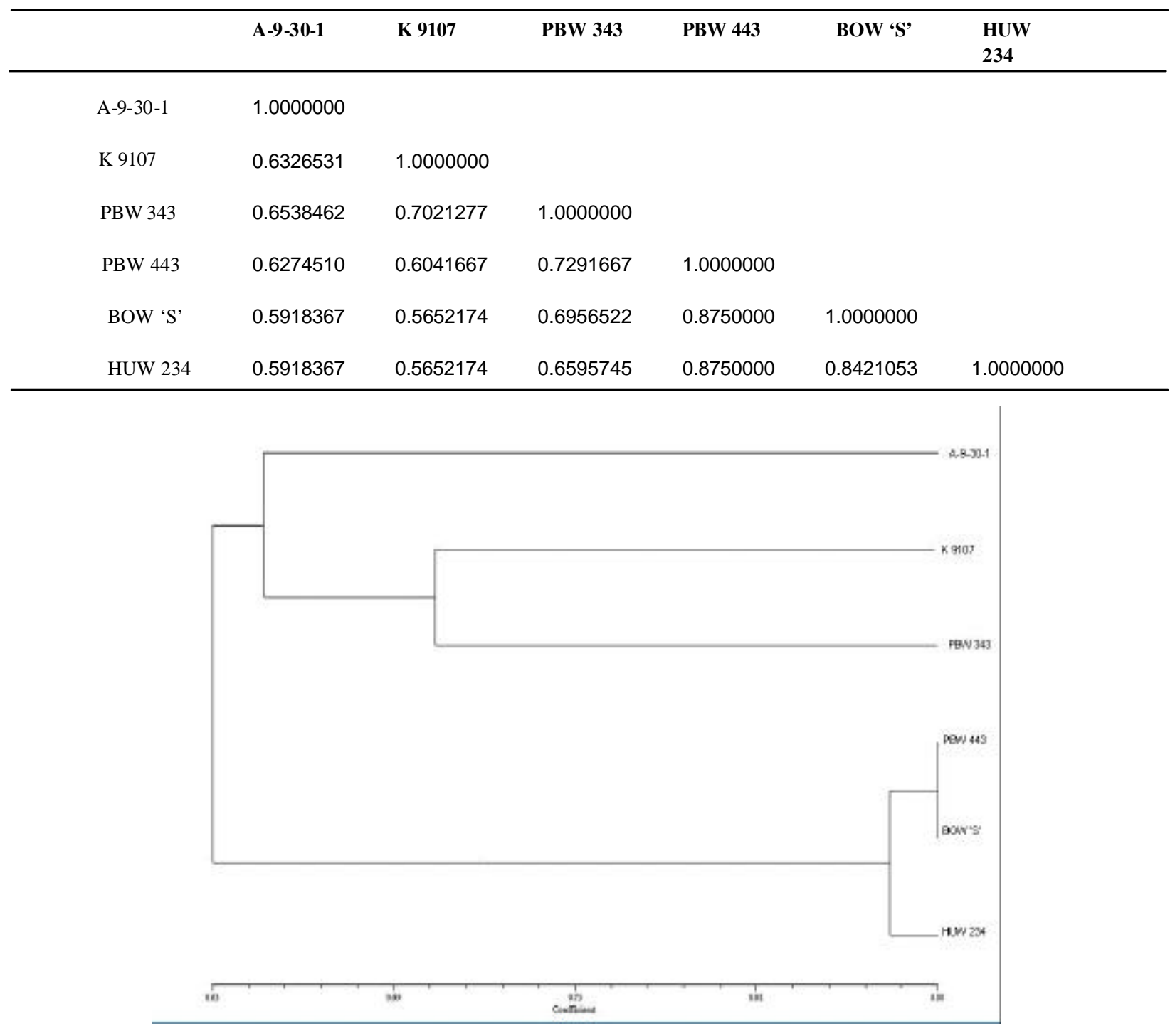

Fig. 1. Dendrogram prepared from RAPD data of six wheat varieties.

more repeated experiments are required which will help to confirm the exact role of individual protein bands in providing either resistance or susceptibility or conferring other phenotypic traits.

DNA profile of wheat varieties: In total 30 primers were used. Out of these 30 Operon primers only 7 primers gave amplification. Details of 7 primers are given in table- 2 . A total 233 fragments resulted from primer amplification with DNA of 6 wheat varieties (Plate-2). There were PCR products common to all the susceptible and resistant wheat varieties. However, there was one polymorphic PCR product $\left(1^{\text {st }}\right)$ with primer AA-09 which was specific to variety PBW-443. The primer W-02 also resulted in one specific PCR product which was only amplified in the variety $\mathrm{PBW}-343$ which was either susceptible or moderately susceptible against majority of the isolates tested. The primer V-07 also resulted in two specific PCR products which amplified in the variety A-9-30-1 which is either susceptible or highly susceptible against all the six isolates. Primer AH-18 also resulted in two susceptibility specific PCR products. However, none of coefficients $\leq 63 \%$. Major group II was divided into two subgroups, with A-9-30-1 in one subgroup and K9107 and PBW 343 in another subgroup, the varieties in subgroup two were having $\leq 70 \%$ similarity.

\section{REFERENCES}

Chauhan, Amit, Singh, R.V. and Singh, Ramji (2007). Cultural and Pathogenic Variability in Bipolaris sorokiniana isolates causing spot blotch of wheat in North India. Indian Phytopath., 60 (4): 472-477. 
Doyle , J.J. and Doyle, J.L. (1990). Isolation of plant DNA from fresh tissue. Focus, 12:13-15.

Dubin,J. (1992). Foliar blight disease scale. Proc., $31^{\text {st }}$ All India Wheat Research Workers Workshop, IARI, New Delhi.

Hetzeler, J., Eyal, Z., Mehta, Y.R. Campos, L.R., Kushnir, U., Zekaria, J. and Cohan, L. (1991). Interaction between spot blotch (Cocnliobolus sativus) and wheat Cultivars. In : Wheat for the Nontraditional warm Areas (Ed. Saunders, D.A.). pp. 146-164. CIMMYT, Mexico City, Mexico.

Joshi, A.K. and Chand, R. (2002). Variation and inheritance of leaf angle and its relationship with resistance to spot blotch in wheat (Triticum aestivum). Euphytica, 124 : 283-291.

Joshi, A.K., Chand, R. and Arun, B. (2002). Relationship of plant height and days to maturity with resistance to spot blotch in wheat (Triticum aestivum). Euphytica, 123: 221228.

Kaur, N., Sharma, R.K., Sharma, M., Singh, V. and Ahuja, P.S. (2007). Molecular evaluation and micropropogation of field selected elites of R.damascene. Gen. Appl. Plant Physiology, 33 (3-4), 171-186.

Kronstad, W.E. (1998). Agricultural development and wheat breeding in the $20^{\text {th }}$ Century, pp.1-10. In :H.J. Brawn F. Allay, W.E.
Laemmli, U.K.(1970). Cleavage of structural proteins during the assembly of the head bacteriophage T4, Nature 227, 680-685

Lowery,R.H., Rose brough, N.J. farr. A.L. Randall L., R.J (1951). Protein measurement with the phenol regent ., Biol.chem. 193. 265-275

Maraite, M., di zinno, T., Longree, H., Daumerie and Duveiller, E. (1998). Fungi associated with foliar blight of wheat in warm areas. In : Helminthosporium Blights of wheat : Spot Blotch and Tan spot. (Eds. Duveiller, E., Dubin, H.J., Reeves, J. and McNab, A.). pp. 293-300. CIMMYT, Mexico City, Mexico.

Shoran, J., Sharma, R.K. and Gupta, R.K. (2005). Efficient inputs management. The Hindu Survey of Indian Agriculture, 47-49.

Singh, A.K., Kumar, S. and Singh, R.N. (2002). Fungicidal management of and avoidable yield loss caused by spot blotch of wheat. Indian Phytopath., 55: 378. 